\title{
Shrouded Attributes, Consumer Myopia, and Information Suppression in Competitive Markets
}

\section{Citation}

Gabaix, Xavier, and David Laibson. 2006. Shrouded attributes, consumer myopia, and information suppression in competitive markets. Quarterly Journal of Economics 121(2): 505-540.

\section{Published Version}

doi:10.1162/qjec.2006.121.2.505

\section{Permanent link}

http://nrs.harvard.edu/urn-3:HUL.InstRepos:4554333

\section{Terms of Use}

This article was downloaded from Harvard University's DASH repository, and is made available under the terms and conditions applicable to Other Posted Material, as set forth at http:// nrs.harvard.edu/urn-3:HUL.InstRepos:dash.current.terms-of-use\#LAA

\section{Share Your Story}

The Harvard community has made this article openly available.

Please share how this access benefits you. Submit a story.

\section{Accessibility}




\title{
SHROUDED ATTRIBUTES, CONSUMER MYOPIA, AND INFORMATION SUPPRESSION IN COMPETITIVE MARKETS*
}

\author{
Xavier Gabaix and David Laibson
}

Bayesian consumers infer that hidden add-on prices (e.g., the cost of ink for a printer) are likely to be high prices. If consumers are Bayesian, firms will not shroud information in equilibrium. However, shrouding may occur in an economy with some myopic (or unaware) consumers. Such shrouding creates an inefficiency, which firms may have an incentive to eliminate by educating their competitors' customers. However, if add-ons have close substitutes, a "curse of debiasing" arises, and firms will not be able to profitably debias consumers by unshrouding add-ons. In equilibrium, two kinds of exploitation coexist. Optimizing firms exploit myopic consumers through marketing schemes that shroud highpriced add-ons. In turn, sophisticated consumers exploit these marketing schemes. It is not possible to profitably drive away the business of sophisticates. It is also not possible to profitably lure either myopes or sophisticates to nonexploitative firms. We show that informational shrouding flourishes even in highly competitive markets, even in markets with costless advertising, and even when the shrouding generates allocational inefficiencies.

\section{INTRODUCTION}

When consumers make mistakes, firms will try to exploit those mistakes. ${ }^{1}$ In some markets, competitive pressure may

* For useful suggestions we thank our editor and referees, Daron Acemoglu, Simon Anderson, Mark Armstrong, Ian Ayres, Robert Barro, Douglas Bernheim, Andrew Caplin, Kenneth Corts, Peter Diamond, Avinash Dixit, Drew Fudenberg, Florian Ederer, Glenn Ellison, Sarah Ellison, Joseph Farrell, Edward Glaeser, Robert Hall, Ali Hortacsu, Sergei Izmalkov, Paul Joskow, Paul Klemperer, Julie Mortimer, Barry Nalebuff, Aviv Nevo, Ariel Pakes, Nancy Rose, José Scheinkman, Andrei Shleifer, Chad Syverson, David Thesmar, Jean Tirole, and seminar participants at the University of California at Berkeley, Columbia University, the Federal Trade Commission, Harvard University, Massachusetts Institute of Technology, National Bureau of Economic Research, New York University, Northwestern, Princeton, Stanford, and Toulouse Universities, the University of Virginia, the Wharton School at the University of Pennsylvania, Yale University, the 2003 European Econometric Society meeting, the 2004 American Economic Association meeting, and the 2004 Duke-Northwestern-Texas Industrial Organization Theory conference. Nathan Barczi, David Borden, Carlos Caro, Steve Joyce, Dominique Olie Lauga, Laura Serban, Kelly Shue, and Chen Zhao provided great research assistance. We acknowledge financial support from the National Science Foundation (SES-0099025). Emails: xgabaix@mit.edu; dlaibson@arrow.fas.harvard.edu.

1. A growing literature models markets in which sophisticated firms interact with consumers who may have psychological biases. For example, see Campbell [2006], DellaVigna and Malmendier [2004], Gabaix, Laibson, and Li [2005], Glaeser [2005], Heidhues and Koszegi [2005], Jin and Leslie [2003], Koszegi and Rabin [forthcoming], Mullainathan and Shleifer [2005], Oster and Morton [2005], Shui and Ausubel [2004], Spiegler [2004], and Ellison [forthcoming] for an overview.

๑ 2006 by the President and Fellows of Harvard College and the Massachusetts Institute of Technology.

The Quarterly Journal of Economics, May 2006 
undermine such exploitation. ${ }^{2}$ For example, competing firms could reveal the exploitation and win over customers. In this paper we identify when such competitive debiasing will and will not occur. We study the market for add-ons-e.g., printer cartridges-and develop ideas related to one proposed by Ellison [2005, subsection V.C], who suggests that some consumers do not think about add-ons when they buy a base good. We formalize this consumer error and determine when competition will lead to debiasing.

Our paper is motivated by the observation that firms choose to hide information from consumers. For example, banks prominently advertise the virtues of their accounts, but the marketing materials do not highlight the costs of such an account which include ATM usage fees, bounced check fees, minimum balance fees, etc. Banks could compete on these costs, but they instead choose to shroud them. Indeed, many bank customers do not learn the details of the fee structure until long after they have opened their accounts.

Cruickshank [2000] reports results of a U. K. Treasury survey that investigates the origins of high fees in the U. K. banking sector. Half of the respondents report having no information about the fees for common financial services at their own bank. ${ }^{3}$ The report concludes that "In the markets to supply banking services to personal customers [. . .] few consumers are aware of the terms and conditions of the products they hold, pointing to significant information problems."

The printer market operates in a similar way. Printer manufacturers advertise the low price of their ink-jet printers, but do not compete on the principal cost of ownership: patented ink cartridges that cost ten times more than the printer itself over the life of the product. Hall [2003] reports that only 3 percent of printer owners claim to know the printing cost at the time they buy their printers. Indeed, printer manufacturers try to make these costs invisible. For example, the printing cost of personal Hewlett-Packard desk-jet printers is not easily accessible on the company's web site. From each printer's home page, one must follow a complex sequence of links to uncover the cost of printing. Such shrouding does not reflect exogenous communication costs.

2. See Becker [1957] and Laibson and Yariv [2005].

3. Respondents were asked "How accurately do you feel you know the charge for services on your account?" Response categories included: "Exactly," "Roughly," "Not at all," and "Did not apply." About half of respondents choose "Not at all." 
The information about printing costs is further away from the printer home page- using the click metric - than any other information about the printer.

At first glance, shrouding add-on prices seems like a natural marketing strategy. However, if consumers are all rational (or aware), shrouding should actually hurt the bank or printer manufacturer, because rational consumers will expect the worse from a firm that shrouds [Jovanovic 1982; Milgrom 1981]. Any information that is hidden in the fine print-or excluded from marketing materials altogether-is not likely to be favorable to consumers. Rational consumers will infer that hidden prices are likely to be high prices. Such reasoning creates an incentive for information revelation and unraveling of shrouding. Indeed, all firms choose to unshroud their prices in equilibria with rational consumers.

We show that shrouding behavior will arise if "myopic" consumers incompletely analyze the future game tree. ${ }^{4}$ Some economists believe that such shrouding cannot survive [Shapiro 1995], arguing that competitive firms should educate other firms' customers, offer those customers efficient pricing schemes, and consequently win their business. In contrast, we show that the existence of myopic consumers creates equilibrium shrouding that is immune to such competitive pressure.

We derive conditions under which competitive price cutting and educational advertising will not occur in equilibrium. We show that debiased consumers prefer to give their business to firms with high shrouded prices because these sophisticated consumers end up with a subsidy from policies designed for myopic customers [DellaVigna and Malmendier 2004, forthcoming]. ${ }^{5}$

To develop intuition for our results, consider a hotel room that costs Hilton $\$ 100$ to supply. Suppose that all consumers are initially myopic (i.e., they do not think about add-ons when they plan a hotel visit). When such a customer stays at Hilton, she ends up paying $\$ 20$ to purchase add-ons like parking, telecommunications, room service, etc. Without loss of generality, assume that these add-ons cost Hilton nothing to provide. In a competitive market, Hilton will then advertise "Hilton's rooms cost only

4. Gabaix, Laibson, Moloche, and Weinberg [forthcoming] analyze a model of partially myopic exploration of game trees. For the lack of Bayesian updating, Simmons and Lynch [1991] present experimental evidence, and Malmendier and Shanthikumar [2005] field evidence.

5. In DellaVigna and Malmendier [2004, forthcoming] cross subsidies arise from self-control problems. Naive consumers who do not recognize their selfcontrol problems cross-subsidize sophisticated consumers who do. 
$\$ 80$," neglecting to mention the costly add-ons that effectively raise its revenue. In competitive equilibrium, Hilton's costs $(\$ 100)$ equal Hilton's total revenues $(\$ 80+\$ 20)$.

Now consider another hotel chain, called Transparent, that is picking a business strategy. Transparent could tell consumers about the shrouded add-ons that consumers pay for at Hilton. ${ }^{6}$ Transparent could advertise, "Watch out for add-on prices at our competitors. Transparent's add-ons are all free." Naturally, if Transparent did this, they could not subsidize their room fees with add-on revenue. An aggressive transparency strategy would be to charge $\$ 100$ for rooms and nothing for add-ons.

Unfortunately, this efficient pricing scheme might not attract any customers. Once consumers understand the high mark-up strategy of Hilton, consumers might prefer to stay at Hilton and simply substitute away from add-on consumption. A "sophisticated" customer anticipates the marked up add-ons at Hilton and avoids buying many of them (e.g., she brings a cell phone instead of relying on the hotel phone, she takes a taxi instead of renting a car that requires parking, etc.). Suppose that the economic cost of such substitution is $\$ 10$. In this case, Hilton's newly educated customers prefer to stay at Hilton rather than defecting to marginal cost pricing at Transparent. Hilton's educated customers receive a $\$ 100$ room for $\$ 80$ and only have to endure a little inconvenience (worth $\$ 10$ ) to avoid buying Hilton's overpriced add-ons. So Transparent's education campaign hurts Hiltonwhich sells fewer add-ons-but helps Hilton's customers, who are taught to substitute away from add-ons. ${ }^{7}$ After the educational advertising campaign, nobody defects to Transparent, even though Transparent has marginal-cost pricing. Hilton is a better deal for sophisticated consumers. Hence, Transparent's unshrouding/advertising campaign does not attract any business. The present paper generalizes this example. ${ }^{8}$

This example also illustrates the curse of debiasing. This curse occurs whenever debiasing makes a consumer less profitable for the debiasing firm. Sophisticated consumers tend to be less profitable because they know how to avoid unnecessary costs.

6. For concreteness, assume that all consumers receive and understand this message and assume that advertising is free. However, the example works no matter what fraction $0<\lambda \leq 1$ of consumers get the message and no matter what it costs to place such advertisements.

7. Of course, Hilton would like to screen out such sophisticated consumers, but this is typically not possible.

8. In the notation of Section II, $c=100, \hat{c}=0, \mu=0, e=10, \alpha=0, \lambda \in$ $(0,1], p=80$, and $\hat{p}=\bar{p}=20$. 
In such cases, firms do not have an incentive to pursue debiasing, and competition will not lead consumers to behave rationally. There are many markets in which firms do not have an incentive to educate their own customers or even the customers of their competitors. Consider the illustrative example above. Debiased Hilton customers, get a $\$ 100$ hotel room for a price of $\$ 80$ plus $\$ 10$ of inconvenience. Hence, the debiased consumer has no reason to defect to Transparent. Accordingly, Transparent (or Hilton) has no incentive to educate Hilton's myopic consumers in the first place. Debiasing a consumer is good for the consumer and bad for both firms. Neither firm has an incentive to do it. ${ }^{9}$

In essence, we show that there are two kinds of exploitation. Firms exploit myopic consumers. In turn, when consumers become sophisticated, they take advantage of these exploitative firms. Finally, when sophisticated consumers exist, firms cannot rid themselves of them. ${ }^{10}$ In equilibrium, nobody has an incentive to deviate except the myopic consumers. But the myopes do not know any better, and often nobody has an incentive to show them the error of their ways. Educating a myopic consumer turns him into a (less profitable) sophisticated consumer who prefers to go to firms with loss-leader base-good pricing and high-priced (but avoidable) add-ons. Hence, education does not help the educating firm.

This mechanism applies to a wide range of markets. An educated banking customer gets the benefit of a $\$ 50$ gift for opening an account and avoids paying some of the fees that snare myopic consumers. An educated credit card holder gets convenience, float, and miles and avoids paying interest charges and late payment fees. ${ }^{11}$ An educated home printer buyer gets a

9. Another example of the curse of debiasing occurs in mutual funds. If a mutual fund company explains that stock picking is not effective and that fees are the primary predictable component in risk-adjusted returns, a newly educated consumer will decide to buy an index fund-a very competitive, and relatively unprofitable, segment of the market. Educating the consumer transforms him into an unprofitable consumer, and for-profit companies will not want to implement such education [Gabaix, Laibson, and Li 2005].

10. In the example above, Hilton cannot drive away educated consumers without also losing its myopic consumers.

11. In recent years, a new shrouding ploy has emerged. For example, Chase offers 0 percent Annual Percentage Rate (APR) on transferred balances. In a footnote in their ads the company acknowledges that "we apply payments to introductory balances before balances with higher APRs [. . .] Learn more about rates, fees, and other cost information by reviewing Pricing \& Terms." In the fine print of Pricing \& Terms, Chase reports, "You authorize us to allocate your payments and credits in a way that is most favorable or convenient for us. For example, you authorize us to apply your payments and credits to balances with lower APRs (such as promotional APRs) before balances with higher APRs." 
loss-leader price and avoids paying for frequent cartridge replacements (by printing in black and white instead of color, printing in draft mode, or printing fewer large jobs at home). ${ }^{12}$ In such markets educated consumers prefer to stick with the firms that feature high add-on prices, since these firms have loss-leader base-good prices, and the educated consumer can partially substitute away from the overpriced add-ons.

Our analysis shows why high add-on markups will persist in markets with numerous competitors and free advertising. This prediction distinguishes our model from standard search models, which imply that firms have an incentive to disseminate information about their products and choose not to do so only if such dissemination is costly (e.g., Bagwell [2005], Butters [1977], Lazear [1995], Salop and Stiglitz [1977], and Stahl [1989]). ${ }^{13} \mathrm{We}$ identify conditions under which firms will choose not to advertise and hence not compete by lowering add-on prices, even when advertising is free. This explains why industries with nearly costless marginal information dissemination still shroud their add-on prices. In a search model with only rational consumers, firms will choose to disclose all of their information if they can do so costlessly. In our model, with enough myopic consumers, shrouding is the more profitable strategy.

As we have explained, our explanation for add-on shrouding and high markups depends on the presence of myopic consumers. ${ }^{14}$ In contrast, many authors have developed rational actor models that explain why add-ons have high markups. However,

Sophisticates can take advantage of this scheme by transferring a balance to Chase and never using the Chase card to make a purchase. In contrast, myopes may fail to realize that they can only repay their new credit card charges (which may accumulate at a high interest rate) after they have repaid their introductory balance (which accumulates at a 0 percent interest rate). We thank Robert Barro for pointing out this example.

12. A sophisticated consumer could also purchase the add-on from a third party, at some transaction cost. This is why base-good firms often hinder such third-party transactions. See Salop [1993] and Hall [2003] for examples.

13. This can be viewed as the key difference between modeling bounded rationality as search costs (e.g., Salop and Stiglitz [1977]), and modeling it directly as failure to anticipate an attribute as in our model. In the search cost approach, if firms can costlessly educate the consumers, they will do so because consumers are Bayesian. If a firm goes out of its way to sustain high search costs, Salop and Stiglitz consumers will rationally infer that it has something to hide. So, if advertising costs are low, all firms reveal information to consumers.

14. In contrast, Ayres and Nalebuff [2003] propose that high add-on prices are partially due to myopic choices on the part of firms, which would make more profits if they had low add-on prices and consequently developed a good reputation. 
these rational models do not explain why firms gratuitously shroud add-on prices. Two types of explanations for high markups figure prominently in the literature: high exogenous search costs $^{15}$ and an inability to commit. ${ }^{16}$

Ellison [2005] proposes a rational price-discrimination model in which add-on pricing enables firms to charge high demand consumers relatively more than low demand consumers. ${ }^{17}$ In Ellison's model, exogenous search costs make it costly for consumers to observe add-on prices. High add-on markups raise profits by facilitating price discrimination. However, Ellison points out that high markups will not be sustainable when information transmission is inexpensive (i.e., when search costs are exogenously small, see Stole [2005]). To handle this case, Ellison suggests an extension that would incorporate unsophisticated consumers who would not buy a base good if they anticipated its total cost including the add-on.

We propose a related model that provides another reason that advertising will reduce sales to formerly irrational consumers. Our model generates a "curse of debiasing": educating a consumer about competitors' add-on schemes effectively teaches that consumer how to profitably exploit those schemes, thereby making it impossible for the educating firm to profitably attract the newly educated consumer. In our setting, unsophisticated consumers fail to take the add-on into account when comparing products. Hence, they only compare the prices of base goods across firms, instead of comparing the total prices (base good plus add-on). When add-ons are made salient-e.g., through advertising-our newly educated consumers do not exit the market, but instead make a more informed choice among the available goods. Our analysis identifies conditions under which no firm has an incentive to educate consumers in this way.

Section II defines a shrouded attribute and presents an equilibrium analysis of a market with discrete demand for add-ons.

15. Search-cost models imply that firms choose high add-on prices because it is exogenously costly for consumers to observe add-on prices before they buy the base good [Diamond 1971; Lal and Matutes 1994; Stahl 1989; Hortacsu and Syverson 2004]. In contrast, our model generates voluntary information suppression.

16. The literature on commitment shows that firms choose high add-on prices if firms cannot commit to add-on prices at the time the base good is sold [Borenstein, MacKie-Mason, and Netz 1995; Farrell and Klemperer 2005; Klemperer 1987]. In our analysis however, we consider the polar case in which firms can commit to an add-on price.

17. See Ellison and Ellison [2004] for related empirical analysis. 
Section III discusses extensions, including the general case with continuous demand for add-ons. Section IV discusses the measurement and regulation of shrouded markets. Section V concludes. All proofs are presented in appendices.

\section{Shrouded Attributes: Definitions And A Model}

We analyze a market in which firms can shroud attributes of their products. These shrouded attributes are not taken into consideration by some potential customers. For example, a bank might suppress information about minimum balance fees in the bank's marketing materials. Some consumers will neglect to consider such fees when picking a bank. For the purposes of our model, a shrouded attribute is a product attribute that is hidden by a firm, even though the attribute could be nearly costlessly revealed. ${ }^{18}$ The Hewlett-Packard decision to omit the desk-jet price per page on their web site is an example of such information suppression.

Shrouded attributes may include surcharges, fees, penalties, accessories, options, or any other hidden feature of the ongoing relationship between a consumer and a firm. We divide this list into two mutually exclusive categories: (avoidable) add-ons and (unavoidable) surcharges.

The analysis in this paper primarily discusses add-ons, the first type of shrouded attribute. Add-ons are complementary goods that consumers have the option to avoid. For example, hotel guests can avoid paying telephone charges if they instead use cell phones. Likewise, hotel guests can avoid paying for room service meals by finding local restaurants. Both hotel phone use and hotel room service complement a hotel stay. Such complementary (voluntary) goods are referred to as add-ons.

In our modeling, we distinguish between a "base good" and the shrouded attribute. In the preceding example, the base good is a hotel room and the shrouded attributes are hotel services. We assume that myopic consumers pick a base good without considering shrouded attributes. ${ }^{19}$

18. More generally, communication costs need to be low enough so that unshrouding would occur in an equilibrium with rational consumers.

19. A consumer can compare prices of closely located four star hotels on a web travel site (e.g., Orbitz), without observing the hotels' add-on pricing schedules. See Ayres and Nalebuff [2003]. 


\section{II.A. Timeline and Overview of (Discrete Demand) Shrouding Game}

We now discuss a model with discrete demand for the add-on. We postpone the general case-i.e., continuous demand-to subsection III.B. We start by providing an overview of the timing of the discrete demand game. We discuss the details of the game after the timeline.

\section{Period 0:}

- Firms decide to make information about the add-on shrouded or unshrouded. This is a binary choice. Unshrouding a price is equivalent to advertising that price. To make unshrouding/advertising maximally attractive to the firm, we assume that unshrouding is free. ${ }^{20}$

- Firms pick prices for a base good $(p)$ and an add-on $(\hat{p})$.

Period 1:

- Sophisticated consumers (fraction $1-\alpha<1$ of the population) always take the add-on and its price into consideration. ${ }^{21}$ If information about the add-on is shrouded, sophisticates form Bayesian posteriors about the unobserved add-on.

- Myopic consumers (fraction $\alpha$ of the population) only consider the add-on if they directly observe the add-on information. When the add-on is shrouded, myopes do not observe the add-on information. When the add-on is unshrouded, fraction $\lambda \in(0,1]$ of myopes observes the add-on information.

- Consumers choose a firm.

- Consumers can initiate costly behavior (effort cost $e$ ) that enables them to substitute away from future use of the add-on.

\section{Period 2:}

- Consumers observe the add-on price (if they have not observed it already) and are given an opportunity to purchase the add-on. Consumers who previously engaged in costly substitution behavior have a lower incentive to purchase the add-on.

20. We revisit this assumption in subsection III.D.

21 . We assume that $\alpha>0$ because the analysis is of interest only when there are myopic consumers. Also, when $\alpha=0$, many combinations of $p$ and $\hat{p}$ are equivalent, as the equilibrium determines only $p+\hat{p}$. 


\section{II.B. Details of the Shrouding Game}

To motivate the model, we will discuss the example of a bank, but the model applies to any setting in which firms offer add-ons to their customers.

Period 0: In period 0, banks set and potentially shroud prices. Let $p$ represent the price of a base good, which in our example is the price of opening a bank account. Let $\hat{p}$ represent the price of an add-on. In our example, violating the minimum balance is an add-on service with price $\hat{p} .^{22}$ Both $p$ and $\hat{p}$ are chosen by each bank in period 0 . Without loss of generality, we assume that banks have zero marginal cost of opening an account or of having an account-holder violate the minimum balance threshold.

Each bank may shroud or unshroud its minimum balance fee. If the bank chooses to shroud $\hat{p}$, the minimum balance fee will not be seen by potential consumers. For example, $\hat{p}$ may be hidden in fine print or published in an obscure location. One can think of this action as creating a gratuitous search cost that is large enough so that few consumers bother to see the add-on price. Without loss of generality, we assume that shrouding implies that no consumer observes the add-on price.

The bank may alternatively costlessly advertise $\hat{p}$, thereby revealing it to all sophisticated consumers and to $\lambda$ fraction of myopic consumers, with $0<\lambda \leq 1$. Without loss of generality we assume that $\lambda$ is fixed. We allow $\lambda$ to be weakly less than unity to reflect the possibility that myopes-who may not initially recognize the value of information about the add-on market-may overlook that information even when it is made available. We define informed myopes as the myopes who have seen (and noted) unshrouded information about the add-on. Informed myopes behave exactly like sophisticated consumers. Analogously, we define uninformed myopes as those myopes who have not seen information about the add-on. Hence, when information is unshrouded by one or more firms, a fraction $\lambda$ of myopes is informed - and therefore become sophisticated—and a fraction 1 $\lambda$ of myopes is uninformed. Hence unshrouding by any firm in-

22. In U. S. banks, a typical minimum balance fee is $\$ 10$ and applies in months when an account balance falls below some minimum that is strictly greater than zero. A minimum balance fee is distinct from an overdraft fee, a bounced-check fee, or an insufficient funds fee. Those fees apply to cases in which customers would like to use funds that they do not have in their accounts. Naturally, the model discussed here applies to those fees as well. 
creases the sophistication of the pool of potential customers shared by all firms. ${ }^{23}$

Period 1: Consumers pick a firm from which to buy the base good. Sophisticates always take the existence of the add-on into consideration, forming Bayesian posteriors about the add-on when its price is shrouded. Myopes only consider the add-on if it is revealed to them.

For a consumer, taking account of the add-on generates two sources of value. First, a consumer can consider add-on pricing when choosing a firm. Second, a consumer who anticipates or observes high add-on prices can exert costly effort $e>0$ in period 1 and thereby substitute away from the add-on. For example, a consumer who faces a high minimum balance fee could transfer balances into the account or cut back withdrawals so that the fee is less likely to be invoked.

We assume that add-on fee $\hat{p}$ is effectively bounded above by $\bar{p}>e .{ }^{24}$ For example, if a customer is forced to pay a high fee, the customer might terminate her relationship with the bank or lodge a complaint. Legal and regulatory constraints also limit the penalties/fees that banks can charge. Finally, $\bar{p}$ could represent the cost of a last-minute consumer intervention that enables the consumer to avoid purchasing the add-on.

We assume that sophisticates and informed myopes are aware of the add-on fee. Hence, sophisticates and informed myopes will exert substitution effort $e$ if $e<E \hat{p} .^{25}$

Let $x_{i}$ represent the anticipated net surplus from opening an account at bank $i$ less the anticipated net surplus from opening an account at the best alternative bank (ignoring idiosyncratic taste differences). Throughout the paper we use starred variables to represent the (symmetric) prices set by other firms. We analyze symmetric equilibria in this paper. ${ }^{26}$

For sophisticated consumers,

$$
x_{i}=\left[-p_{i}-\min \{E \hat{p}, e\}\right]-\left[-p^{*}-\min \left\{E \hat{p}^{*}, e\right\}\right],
$$

23. Assuming that the impact of advertising is more local would not change our results.

24. If the add-on is unavoidable $(e>\bar{p})$ and consumers are not all sophisticated $(\lambda<1, \alpha>0)$, then the proof of Proposition 1 shows that there is a unique sequential equilibrium, which has Shrouded Prices and $p=-\bar{p}+\mu, \hat{p}=\bar{p}$.

25 . We assume local risk neutrality throughout the paper. Also, it is important that informed myopes behave like sophisticates.

26 . Technically, our equilibrium is a sequential equilibrium, as detailed in the preamble of the proof of Proposition 1. 
where $E \hat{p}$ and $E \hat{p}^{*}$ are the rational expectations about the add-on price of the firm, and its competitors, respectively. When the add-on information is unshrouded, expectations are equal to the true value of the add-on price. When the add-on information is shrouded, sophisticated consumers solve the Bayesian equilibrium to calculate $E \hat{p}$ and $E \hat{p}^{*}{ }^{27}$

Myopic consumers fall into two classes. When add-on prices are unshrouded, a fraction $\lambda$ of myopes becomes informed. These informed myopes behave just like sophisticates with $E \hat{p}=\hat{p}$. A myope who was educated by firm $i$ becomes sophisticated in his behavior vis-à-vis all firms. However, even when add-on information is unshrouded, a fraction $1-\lambda$ of myopes remains uninformed. When add-on information is shrouded, all myopes are uninformed.

For uninformed myopes,

$$
x_{i}=-p_{i}+p^{*} .
$$

Uninformed myopes neglect the add-on when deciding where to open their bank account. Likewise, uninformed myopic consumers do not consider exerting substitution effort $e$ in period 1 .

Let $D\left(x_{i}\right)$ represent the probability that a consumer opens an account at bank $i$. Recall that $x_{i}$ represents the average anticipated net surplus from opening an account at bank $i$ less the average anticipated net surplus from opening an account at the best alternative bank. The demand function $D$ is strictly increasing, bounded below by zero, and bounded above by one. Appendix 1 presents a microfoundation of the demand function. The demand function allows us to flexibly parameterize the degree of competition in the industry, via the quantity $\mu=D(0) / D^{\prime}(0)$, which will turn out to be equal to the average profit per consumer. In particular, perfect competition corresponds to $\mu=0$.

Period 2: Consumers observe the add-on price (if they have not observed it already) and are given an opportunity to purchase the add-on. Consumers who have engaged in substitution in period 1 do not purchase the add-on. All other consumers purchase the add-on at price $\hat{p} .{ }^{28}$

27. We commit some abuse of language here. When the add-on information is shrouded, the sophisticated consumers' beliefs are part of a consistent assessment (i.e., a strategic profile and a belief system), in particular they anticipate perfectly the price that the firm charges in equilibrium.

28. Alternatively, we could assume that uninformed myopes buy the add-on in period 2 without observing the price: i.e., the myopes believe that the unobserved add-on price is low enough to justify the purchase. 


\section{II.C. Symmetric Equilibrium}

We now characterize the symmetric sequential equilibrium of this game. ${ }^{29}$ Let $\alpha$ represent the share of myopic consumers in the marketplace. The following proposition shows that firms will choose high markups in the add-on market. In the Shrouded Prices Equilibrium, firms will choose markups that are so high that the sophisticated consumers substitute out of the add-on market.

Proposition 1. Let

$$
\alpha^{\dagger} \equiv e / \bar{p}
$$

and

$$
\mu=D(0) / D^{\prime}(0) .
$$

If the fraction of myopic consumers $\alpha$ is greater than $\alpha^{\dagger}$, there exists a symmetric equilibrium in which firms shroud the add-on price. Call this the Shrouded Prices Equilibrium. The prices of the base good and the add-on are, respectively,

$$
\begin{gathered}
p=-\alpha \bar{p}+\mu \\
\hat{p}=\bar{p} .
\end{gathered}
$$

In this equilibrium only myopes purchase the add-on. The allocation is inefficient since sophisticates substitute away from the add-on.

If the fraction of myopic consumers $\alpha$ is less than $\alpha^{\dagger}$, there exists a symmetric equilibrium in which firms do not shroud the add-on price. Call this the Unshrouded Prices Equilibrium. The prices of the base good and the add-on are, respectively,

$$
\begin{gathered}
p=-e+\mu \\
\hat{p}=e .
\end{gathered}
$$

In this equilibrium all consumers purchase the add-on, so the equilibrium is efficient. In each of these equilibria the beliefs of sophisticated consumers and educated myopes are $\hat{p}=\bar{p}$ for the add-on price at a firm that shrouds, independently of its base-good price. Also, the total profits of the industry are $\mu$.

29. The proof of Proposition 1, in Appendix 2, provides the details of the strategies and beliefs. 
The proof is in Appendix 2.

Proposition 1 characterizes a Shrouded Prices Equilibrium ${ }^{30}$ in which firms choose inefficiently high markups in the add-on market and choose to shroud those add-on prices. ${ }^{31}$ In the Shrouded Prices Equilibrium, firms set $\hat{p}^{*}=\bar{p}$, though the marginal cost of producing the add-on is 0 . This equilibrium is inefficient since the sophisticates pay effort cost $e$ to substitute away from add-on consumption (see subsection II.D below).

Our model reproduces the well-known result that high markups for the add-on are offset by low or negative markups on the base good. ${ }^{32}$ This is easiest to see when the market is approximately competitive (i.e., the demand curve is highly elastic, and hence $\mu$ is close to zero). In a relatively competitive market with small $\mu$, the base good is always a loss leader with a negative markup: $p^{*} \approx-\alpha \bar{p}<0$ or $p^{*} \approx-e<0$. The model implies that the add-on will be the "profit-center" and the base good will be the "loss leader." 33

Our model also predicts equilibrium shrouding, as conjectured by Ellison [2005]. Other previous authors have conjectured that the availability of inexpensive advertising would drive down aftermarket prices and eliminate shrouding. For example, Shapiro [1995] describes the inefficiency caused by high markups in the aftermarket and then observes that competition and advertising should drive them away.

Furthermore, manufacturers in a competitive equipment market have incentives to avoid even this inefficiency by providing information to consumers. A manufacturer could capture profits by raising its [base-good] prices above market levels (i.e., closer to cost), lowering its aftermarket prices below market levels (i.e., closer to cost), and informing buyers that its overall systems price is at or below market. In this fashion, the manufacturer could eliminate some or all of the deadweight loss, attract consumers by offering a lower total cost of ownership, and still capture as profits some of the elimi-

30. It is easy to see that if $\alpha-\lambda \alpha>\alpha^{\dagger}$ and there is a small cost of unshrouding, then the Shrouded Prices Equilibrium is the unique symmetric sequential equilibrium. When $\lambda$ is large enough, another equilibrium exists. Specifically, when $\alpha>\alpha^{\dagger}>\alpha-\lambda \alpha$, the Shrouded Prices and Unshrouded Prices Equilibria both exist.

31. For empirical applications, we reexpress Proposition 1 in the case where the marginal costs $c$ and $\hat{c} \leq e$ are not zero. In this case, if $\alpha>\alpha^{\dagger}, p=c-\alpha(\bar{p}-$ $\hat{c})+\mu$, and if $\alpha<\alpha^{\dagger}, p=c+\hat{c}-e+\mu$. The value of $\hat{p}$ does not change.

32. See the literature review in the present paper and in Ellison [2005].

33. In many seemingly competitive markets the price of the base good is typically set below its marginal cost (e.g., printer, hotel, car rental, financial services), while the price of the add-on is set well above its marginal cost (printer cartridge, hotel phone call, gas charge, minimum balance fee). 
nated deadweight loss. In other words, and unlike traditional monopoly power, the manufacturers have a direct incentive to eliminate even the small inefficiency caused by poor consumer information [Shapiro 1995, p. 495].

In the Shrouded Prices Equilibrium, Shapiro's intuition about inefficiency applies, but his anticipated unshrouding effects are overturned by other forces. In general, high markups in the aftermarket do not go away as a result of competition or advertising.

Why does Shapiro's unshrouding effect not arise? Shapiro conjectures that firms will compete by advertising low add-on prices, thereby attracting consumers by highlighting the benefits of efficiently priced add-ons.

However, Proposition 1 shows that this competitive effect is overturned by a "curse of debiasing." Specifically, educated consumers would prefer to frequent firms with high add-on prices that they can avoid rather than defecting to firms with marginal cost pricing of both the base good and the add-on.

Again consider the illustrative case of perfect competition, $\mu=0$. If a sophisticated consumer gives her business to a firm with shrouded market prices, the sophisticated consumer's surplus will be

$$
\begin{aligned}
\text { sophisticated surplus } & =-p-e \\
& =\alpha \bar{p}-e \\
& >\alpha \bar{p}-\alpha \bar{p}=0 .
\end{aligned}
$$

By contrast, if the sophisticated consumer gives her business to a firm with zero markups on both the base-good and the add-on, the sophisticate's surplus will be exactly $0 .{ }^{34}$ So the sophisticated/ educated consumer is strictly better off at the firm with shrouded prices (and high add-on markups), than at the firm with marginal cost pricing.

This preference for the firms with high markups reflects the fact that the sophisticated consumers are subsidized by pricing policies designed for uninformed myopic consumers. Educating uninformed myopes enables them to get more value out of their relationships with high markup firms. After education, myopes anticipate the high add-on prices, and hence substitute away from add-ons while still enjoying loss-leader prices on the base

34. The particular value of a 0 surplus depends on the choice of normalization. If we shift all utilities by a factor $V$, the surplus will be $V$. 
good. The newly educated consumers benefit from the "free gifts" and avoid the high fees. ${ }^{35}$

This generates the curse of debiasing. A firm does not benefit by debiasing uninformed myopic consumers. Newly educated consumers (i.e., sophisticates) are not profitable to any firm. Specifically, sophisticates prefer to patronize-and in particular, exploit-firms that offer loss-leader prices on base goods.

This intuitive analysis explores pricing deviations in which a firm tries to educate and attract myopes from other firms (using low markups as the lure). Naturally, equilibrium analysis must also analyze deviations in which a firm with high markups tries to drive away (money-losing) sophisticates. Naturally, both deviations must be considered in the proofs of Proposition 1.

In summary, the presence of uninformed myopic consumers incentivizes firms to adopt pricing schedules that have the unintended consequence of subsidizing sophisticates. Making more myopes sophisticated will not help any firm. Because of this curse of debiasing, no firm has an incentive to educate myopes, even when education is costless.

\section{II.D. Welfare}

We now provide a welfare analysis of the Shrouded Prices Equilibrium and highlight the inefficiency of this equilibrium. ${ }^{36}$

Proposition 2. In the Shrouded Prices Equilibrium the social welfare loss is $\Lambda=(1-\alpha) e$. Sophisticated consumers are $\bar{p}-e$ units better off than myopic consumers. In the Unshrouded Prices Equilibrium, there is no inefficiency, and all consumers are equally well-off.

Proof of Proposition 2. The social welfare loss is proportional (with factor $e$ ) to the fraction of agents that exerts costly effort $e$ to avoid consuming the add-on. Recall that the firms can produce the add-on at 0 marginal cost. In the Shrouded Prices Equilibrium all of the sophisticated agents exert effort $e$, so the deadweight loss is $(1-\alpha) e$. Also, as sophisticates pay $e$ to avoid

35. In Proposition 1, indeed, one needs $\lambda>0$, but otherwise the specific value of $\lambda$ does not matter. The reason is clear from the proof. Sophisticates are less profitable than myopes, so after unshrouding an increase in the number of sophisticates, caused by $\lambda>0$, reduces total profits.

36. As often in welfare economics, the pricing distortion is likely to have greater redistributional effects than net efficiency losses. 
buying the add-on, and myopes pay $\bar{p}$, sophisticates are $\bar{p}-e$ better off than myopes.

In the Unshrouded Prices Equilibrium no consumers exert costly effort, and all purchase the add-on, which is produced at 0 marginal cost. There is no efficiency loss.

Since the add-on can be produced at zero social cost, ${ }^{37}$ it is socially efficient for the add-on to be consumed. If a consumer substitutes away from the add-on (at effort cost $e$ ), then an equilibrium is socially inefficient. In the case with inefficiency $\left(\alpha>\alpha^{\dagger}\right)$, the welfare losses increase as the fraction of sophisticates increases; in this case sophisticates do not consume the (high-priced) add-on.

\section{EXTENSIONS}

In this section we discuss several extensions of the model. First, we discuss the case in which myopes learn to become sophisticates. Second, we analyze the case of continuous demand for the add-on. Finally, we discuss a series of additional considerations that influence the persistence of shrouding.

\section{III.A. Learning}

In some markets, myopes eventually learn the high price of the add-on, thereby becoming sophisticates. We present an extension that reflects this learning process and demonstrate how learning affects equilibrium pricing.

We adopt the same timing as before, but now we assume that the decision about add-on consumption is repeated. Specifically, after choosing a firm from which to buy the base good, sophisticates face the add-on purchase decision $T_{S}$ times. For each decision, sophisticates decide whether to pay avoidance cost $e$ or buy the add-on for price $\hat{p}$. Informed myopes act just like sophisticates. Uninformed myopes buy the add-on $T_{M M}$ times. ${ }^{38}$ They then become sophisticates and make sophisticated choices $T_{M S}$ times. ${ }^{39}$ Our original model corresponds to $T_{S}=T_{M M}=1$ and

37. This assumption is made without loss of generality.

38. In practice, the propensity to become sophisticated should increase with the cost of behaving myopically. This would lead to an interesting extension of the framework.

39. In some cases it may be natural to assume that $T_{S}=T_{M M}+T_{M S}$, but we do not make this assumption here, the Shrouded Prices Equilibrium does not depend on it. 
$T_{M S}=0 .{ }^{40}$ We assume that firms choose their shrouding policies and prices once and for all and do not change them during the game.

The following Proposition shows that there is a Shrouded Prices Equilibrium if the fraction of myopes $\alpha$ is high.

Proposition 3. Let

$$
\alpha^{\dagger \dagger} \equiv \frac{e}{\overline{\bar{p}}} \frac{\max \left(T_{S}, T_{M M}+T_{M S}\right)}{T_{M M}} .
$$

If $\alpha>\alpha^{\dagger \dagger}$, then there exists a symmetric equilibrium in which firms shroud the add-on pricing. Call this the Shrouded Prices Equilibrium:

$$
\begin{aligned}
& p=-\alpha \bar{p} T_{M M}+\mu \\
& \hat{p}=\bar{p} .
\end{aligned}
$$

In this equilibrium the myopes purchase the add-on until they become sophisticates. The allocation is socially inefficient since sophisticates substitute away from the add-on. The beliefs of sophisticated consumers and educated myopes are $\hat{p}=\bar{p}$ for the add-on price at firms that shroud.

The myopia model predicts that consumers will eventually learn to avoid add-on fees. Agarwal et al. [2005] empirically evaluate these dynamics, confirming the prediction that add-on fees in banks decline with customer tenure. This learning pattern is inconsistent with the predictions of a classical price discrimination model of add-on pricing.

Our analysis raises the question of long-run dynamics. If consumers learn to avoid add-on fees, does shrouding eventually vanish along with high add-on prices? Several countervailing forces may sustain shrouding in the long run. First, new generations of myopic consumers enter the market. Second, sophistication is sometimes overturned by forgetting or distraction, particularly when the absolute costs of the add-on are small. Third, and most importantly, new shrouding techniques endogenously evolve. For example, the emphasis on fee-based revenue in the banking sector is a recent development [Rogers and Sinkey 1999].

We believe that fees for specific add-ons have a life cycle. When the add-on is new, it tends to be shrouded and priced above

40. See Miao [2005] for another analysis. 
marginal cost. Over time, shrouding decreases, and the add-on price falls. Using our notation, the fraction $\alpha$ of myopes decreases over time, and shrouding eventually disappears. ${ }^{41}$

\section{III.B. Continuous Add-on Demand}

In this subsection we generalize the model to the case of continuous demand for the add-on. We show that equilibrium shrouding survives only when sophisticates have relatively inexpensive substitutes for the add-on. The structure and timing of the game in this section mirrors the details of the original game except for the extensions enumerated below.

Total consumer utility is decomposed into two parts: the value of owning the base good and the cost of purchasing-or substituting away from-the add-on. Let $u_{a i}$ represent agent $a$ 's value of firm $i$ 's base good, overlooking the add-on. ${ }^{42}$ Let $\hat{u}\left(\hat{e}_{a i}, \hat{q}_{a i}\right)-\hat{p}_{i} \hat{q}_{a i}$ represent the costs associated with the add-on, reflecting both the add-on quantity $\hat{q}_{a i}$ and any costly efforts $\hat{e}_{a i}$ to substitute away from the add-on. The leading case is $\partial^{2} \hat{u}\left(\hat{e}_{a i}, \hat{q}_{a i}\right) / \partial \hat{e}_{a i} \partial \hat{q}_{a i} \leq 0$. The net value of buying the base good can be written as

$$
\underbrace{u_{a i}-p_{i}}_{\text {base-good utility }}+\underbrace{\hat{u}\left(\hat{e}_{a i}, \hat{q}_{a i}\right)-\hat{p}_{i} \hat{q}_{a i} \text {. }}_{\text {add-on utility }}
$$

In period 1, sophisticated consumer a picks a firm $i$ and substitution effort $\hat{e}_{a i}$ to maximize

$$
U_{a i}=u_{a i}-p_{i}+\max _{\hat{e}_{a i}} E\left\{\max _{\hat{q}_{a i}}\left[\hat{u}\left(\hat{e}_{a i}, \hat{q}_{a i}\right)-\hat{p}_{i} \hat{q}_{a i}\right]\right\} .
$$

In period 2, sophisticates pick $\hat{q}_{a i}$ to maximize $\hat{u}\left(\hat{e}_{a i}, \hat{q}_{a i}\right)-\hat{p}_{i} \hat{q}_{a i}$. We call $\hat{u}^{S}\left(\hat{p}_{i}\right)=\hat{u}\left(\hat{e}_{a i}, \hat{q}_{a i}\right)$ the corresponding indirect utility for the rational expectations case in which $\hat{p}_{i}=E \hat{p}_{i} \cdot{ }^{43}$

Informed myopes behave just like sophisticates, since informed myopes observe the add-on information in period 1 .

In contrast, uninformed myopes do not take account of the add-on when they pick a firm $i$. In period 1 , uninformed myopes pick a firm $i$ to maximize $u_{a i}-p_{i}$.

Uninformed myopes passively choose a default level of sub-

41. We thank Douglas Bernheim for suggesting these life-cycle dynamics.

42. For example $u_{a i}$ could represent the value of the base good assuming a zero price for the add-on.

43. $\hat{u}^{S}\left(\hat{p}_{i}\right)=\hat{u}\left(\hat{e}_{a i}, \hat{q}_{a i}\right)=\hat{u}\left(\hat{e}_{a i}\left(E \hat{p}_{i}\right), \hat{q}_{a i}\left(\hat{e}_{a i}\left(E \hat{p}_{i}\right), \hat{p}_{i}\right)\right)=\hat{u}\left(\hat{e}_{a i}\left(\hat{p}_{i}\right)\right.$, $\left.\hat{q}_{a i}\left(\hat{e}_{a i}\left(\hat{p}_{i}\right), \hat{p}_{i}\right)\right)$. 
stitution effort in period $1 \hat{e}_{a i}^{M}$ which is not responsive to shrouded variation in $\hat{p}_{i}$. In period 2 , uninformed myopes pick $\hat{q}_{a i}$ to maximize $\hat{u}\left(\hat{e}_{a i}^{M}, \hat{q}_{a i}\right)-\hat{p}_{i} \hat{q}_{a i}$.

We call $c$ the marginal cost of the base good and $\hat{c}$ the marginal cost of manufacturing the add-on. Let $\hat{q}^{S}(\hat{p})$ represent the equilibrium add-on demand of a sophisticate who knows she will face a price $\hat{p}$. Let $\hat{q}^{M}(\hat{p})$ represent the equilibrium add-on demand of an uninformed myopic who initially overlooks add-on prices because they are shrouded. We assume that there is a unique monopoly price in the add-on market, given by

$$
\hat{p}^{m}=\arg \max _{\hat{p}}(\hat{p}-\hat{c})\left[(1-\alpha) \hat{q}^{S}(\hat{p})+\alpha \hat{q}^{M}(\hat{p})\right] .
$$

Now we characterize symmetric sequential equilibria.

Proposition 4. Suppose that unshrouding makes all consumers sophisticated $(\lambda=1)$. The price vector

$$
\begin{gathered}
p=c-(\hat{p}-\hat{c}) \hat{\bar{q}}(\hat{p})+\mu \\
\hat{p}=\hat{p}^{m}
\end{gathered}
$$

supports a Shrouded Prices Equilibrium if and only if $B \geq 1$, where $B$ is the debiasing ratio:

$$
B=\frac{\text { cross subsidy to sophisticates from myopes }}{\text { loss of social surplus (for sophisticate demand) }}
$$

The beliefs of sophisticated consumers and educated myopes are $\hat{p}=\hat{p}^{m}$ for the add-on price at firms that shroud.

The proof is in Appendix 2.

This no-advertising result contains a boundary condition that determines when advertising will appear: $B \geq 1 .{ }^{44}$ Advertising does not arise when the cross subsidies to sophisticates are larger than the social welfare distortions due to price deviations

44. With the discrete demand model of Section II, the subsidy is $\alpha \bar{p}$, the distortion is $e$, so $B=B^{\prime}=\alpha \bar{p} / e$. Condition $B \geq 1$ is $\alpha \geq \alpha^{\dagger}$, reproducing the result of Proposition 1. 
from marginal cost. An empirical test of this theory would calculate $B$ ratios in different markets, and determine whether markets with high $B$ values tend to be more shrouded.

To heuristically derive the result, consider another ratio that is easier to directly interpret:

$$
\begin{gathered}
B^{\prime}=\frac{\text { loss-leader subsidy in base-good market }}{\text { loss of consumer surplus (for sophisticate demand) }} \\
\text { due to add-on markup } \\
=\frac{\left(\hat{p}^{m}-\hat{c}\right)\left[(1-\alpha) \hat{q}^{S}\left(\hat{p}^{m}\right)+\alpha \hat{q}^{M}\left(\hat{p}^{m}\right)\right]}{\left[\hat{u}^{S}(\hat{c})-\hat{c} \hat{q}^{S}(\hat{c})\right]-\left[\hat{u}^{S}\left(\hat{p}^{m}\right)-\hat{p}^{m} \hat{q}^{S}\left(\hat{p}^{m}\right)\right]} .
\end{gathered}
$$

A sophisticate at a shrouded firm will not defect to a marginal cost pricing firm if the loss-leader subsidy in the base-good market exceeds the consumer welfare gain from switching to marginal cost pricing in the add-on market (i.e., $B^{\prime} \geq 1$ ). Since aftermarket profit generates loss-leader competition in the basegood market, the loss-leader base-good subsidy is $\left(\hat{p}^{m}-\hat{c}\right)[(1-$ $\left.\alpha) \hat{q}^{S}\left(\hat{p}^{m}\right)+\alpha \hat{q}^{M}\left(\hat{p}^{m}\right)\right]$, which is the average profit per customer in the add-on market. The denominator of $B^{\prime}$ is the sophisticates' welfare loss from high markups in the add-on market. At marginal cost pricing $(\hat{p}=\hat{c})$, the sophisticate would realize add-on utility of $\hat{u}^{S}(\hat{c})-\hat{c} \hat{q}^{S}(\hat{c})$, but in the shrouded prices equilibrium the sophisticate pays add-on price $\hat{p}^{m}$ and realizes a lower add-on utility of $\hat{u}^{S}\left(\hat{p}^{m}\right)-\hat{p}^{m} \hat{q}^{S}\left(\hat{p}^{m}\right)$. Putting these results together, we get the expression of $B^{\prime}$ in equation (15). We can recover $B$ (equation (13)) by subtracting $\left(\hat{p}^{m}-\hat{c}\right) \hat{q}^{S}\left(\hat{p}^{m}\right)$ from both the numerator and denominator of $B^{\prime}$. Hence $B \geq 1$ iff $B^{\prime} \geq 1$.

\section{III.C. Additional Models of Shrouded Equilibria}

In this subsection we discuss some tractable variants of our model that are empirically relevant. One variant is that of "observable prices but limited awareness." ${ }^{\prime 4}$ In this version the prices of all firms are always observable, at no cost, by all consumers. Myopes, however, just do not consider (or even think of) the price of the add-on. In contrast, sophisticates costlessly observe and take into account the add-on prices of all firms. If a firm "unshrouds," it educates the myopes (or a fraction $\lambda$ of them), and

45. This variant is developed in the May 2004 version of the present paper, which is available upon request. 
makes them aware of the existence of the add-on. The results of this variant are very close to the results of the present framework. The results of Proposition 1-the discrete demand model - do not change. The results of Proposition 4-the continuous demand model-do not change, except that the add-on price charged in the Shrouded Equilibrium falls between marginal cost and the monopoly price. The reason is that, if a firm lowers the price of the add-on, it gets more sophisticated consumers.

In another variant, myopic consumers simply underestimate their use of the add-on. ${ }^{46}$ This variant is relevant when consumers are overoptimistic about the use of credit cards [Ausubel 1991] or lines of credit [Landier and Thesmar 2005]. Such a microfoundation would not change the results of the present paper.

The model also makes predictions about which attributes will be shrouded, for a given good. Indeed, one can generalize the model to a good with several shrouded attributes, which may have different values for $\alpha, e$, and $\bar{p}$. Our Proposition 1 also applies to each attribute. There will be a Shrouded Prices Equilibrium for an attribute if $\alpha>e / \bar{p}$ for that attribute. Hence an attribute will be shrouded if its debiasing ratio $B=\alpha \bar{p} / e$ is greater than 1 .

\section{III.D. Other Influences on Shrouding}

To simplify exposition, we have ignored several additional factors that influence the prevalence of shrouding. In this subsection we quickly discuss these factors, starting with the factors that encourage shrouding. First, we have so far overlooked the consumer entry decision, since we have assumed that all consumers must buy a base good. When some consumers overlook add-on costs, these myopic consumers may buy the base good when they should avoid the market altogether [Ellison 2005]. Think of a consumer who buys a $\$ 50$ desk-jet printer without realizing that the lifetime operating costs are at least ten times higher. ${ }^{47}$ Firms that compete by unshrouding high add-on prices will drive some of these myopic consumers out of the base-good market. Hence, consumer entry decisions are adversely affected by unshrouding [Spence 1977].

46. Subsection 7.3 of our 2004 working paper.

47. At the moment, black and white text costs between 2 cents and 15 cents per page, depending on the ink-jet printer. Color text costs more than black and white text. A photographic image costs an order of magnitude more. Printing ten pages per day at only 10 cents a page costs $\$ 1460$ over four years. 
Second, we have so far assumed that once a consumer becomes informed about the costly add-on at one firm, that consumer takes account of the costly add-ons at all firms. However, it is instead possible that unshrouding by one firm leads consumers only to think about the unshrouded add-on at that single firm. This narrow framing effect would impede unshrouding.

Third, if education/advertising is costly, then unshrouding will again be impeded. Specifically, suppose that there is a fixed cost $C$ of unshrouding. Then Proposition 4 is adjusted so that a Shrouded Prices Equilibrium exists iff $B \geq 1$, where $B$ is defined as before except the numerator of $B$ is incremented by $k C$, where $k=1$ if $\mu=0$ and $k$ equals the number of firms if $\mu$ is very large. ${ }^{48}$ Analogously, Proposition 1 is adjusted so that a Shrouded Prices Equilibrium exists iff $\alpha \bar{p}+k C>e$. This implies that shrouding is more pervasive when the market is less competitive.

Fourth, we have already mentioned that learning will accelerate unshrouding. However, innovation will create new add-ons and new opportunities for shrouding.

Some forces besides learning, however, will favor unshrouding. For instance, if consumers have heterogeneous tastes and firms have heterogeneous add-ons, firms will advertise to enable consumers to find the base good with the right add-on. This informative advertising will accelerate unshrouding.

Also, third party consumer education-e.g., magazines like Consumer Reports-will accelerate unshrouding. However, various impediments prevent such educational mechanisms from working perfectly. Nonprofit educational organizations may be underfinanced. Moreover, for-profit educational organizations may have incentives to give bad advice. For example, personal finance magazines tend to recommend active portfolio management, thereby justifying ongoing demand for these magazines. Consumers may not know which adviser to trust.

\section{Measuring and Regulating Shrouding}

In this section we discuss the measurement and regulation of shrouding. We first consider the problem of a regulator-or an economic researcher-who wishes to empirically identify the ex-

48. The proof is a simple modification of the proofs of Propositions 1 and 4, with a Taylor expansion when $\mu$ is very large. 
istence of shrouding. We then consider potential regulatory remedies, emphasizing both the benefits and pitfalls of these policies.

\section{IV.A. Measuring Shrouding: Diagnostics}

Five different empirical strategies can be used to identify the existence of shrouding. First, researchers may conduct consumer surveys. Such surveys would determine whether consumers at the point of purchase are aware of the add-on costs that they will later face. This corresponds to measuring $1-\alpha$, an index of average "consumer I.Q." For example, Hall [2003] finds that only 3 percent of consumers who buy desk-jet printers know the associated ink costs at the time they purchase the printer. ${ }^{49}$ Of course, such ignorance may or may not imply shrouding (e.g., ignorance may result from exogenously high search costs). Consumer surveys might also test for incorrect consumer expectations. For example, at the point of purchase consumers could be asked to estimate their ink costs. In shrouded equilibria, a large fraction of consumers should underestimate such costs (and relatively few consumers should overestimate those costs). Naturally, whenever possible, surveys should use incentive-compatible designs. For example, respondents could be told to estimate the ink costs of a consumer who prints a specific number of pages per month and uses nongeneric cartridges. With such a setup, accurate beliefs could be financially rewarded.

Second, researchers could test comparative statics assumed or predicted by the model. The model assumes that consumers show a greater response to up-front costs than to delayed costs. More generally, the model assumes that consumers show a relatively muted response to complex, contingent, camouflaged, distant, or disaggregated costs. Hausman [1979] and Hausman and Joskow [1982] find that consumers are far more responsive to the store prices of appliances (e.g., refrigerators) than to the net present value of the energy costs of operating the appliances. Barber, Odean, and Zheng [forthcoming] show that mutual fund investors are more sensitive to front-end loads than to ongoing management fees. Hossain and Morgan [2005, 2006] find that consumers are more responsive to direct costs than to shipping charges, and more generally find field evidence for shrouded

49. Office of Fair Trading [2002] provides related evidence. 
attributes. ${ }^{50}$ Bertrand et al. [2005] find that field evidence for the importance of framing in marketing materials. Researchers could also study comparative statics by conducting controlled experiments. A control group might receive standard (shrouded) marketing materials. A treatment group would see the standard marketing material as well as an unshrouded statement of the add-on costs. Choi et al. [2005] conduct a field experiment with the structure above. They find that MBA students avoid investing in mutual funds with high management fees only when those fees are explicitly unshrouded with an exogenous intervention.

Third, researchers could also determine whether firms gratuitously increase the search cost for add-on prices. For instance, firms may make add-on prices much harder to find than other less important information.

Fourth, researchers may conduct product audits, which determine if base goods are being sold at loss-leader prices and if add-ons are being sold at high markups. Of course, loss-leader base goods and high markups on add-ons are only necessary conditions for the existence of a shrouded equilibrium.

Fifth, regulators could look for learning effects implied by shrouded equilibria. If fees are initially shrouded and consumers encounter these fees as they gain more experience with a product, then consumers will slowly learn to avoid these fees (see subsection III.A). Indeed, the logic of shrouding implies that learning effects may generate reduced-form preference reversals. For example, consider two bank account holders: one consumer just triggered an add-on fee, and the other consumer did not. The consumer who just "bought" the add-on will have a lower future add-on demand compared with the consumer who did not buy the add-on (since the latter consumer has a higher chance of still being unaware of the add-on trap). Such dynamic demand reversals contradict standard theories of add-on demand, which feature consumer heterogeneity and price discrimination. Agarwal et al. [2005] find learning effects in the retail banking market. Other authors have argued that consumers with a better general education get better prices in the marketplace. Woodward [2003] finds that more educated consumers pay less in the mortgage market controlling for default risk. Controlled field experiments can be designed to identify the effect of unshrouding.

50. Morwitz, Greenleaf, and Johnson [1998] find related experimental evidence. 


\section{IV.B. Regulatory Interventions}

Shrouded equilibria generate economic inefficiencies. However, regulatory remedies may not be available. It is difficult to outlaw ignorance or misleading (but accurate) marketing. If regulators find evidence for inefficient shrouding, they have four types of (imperfect) regulatory remedies that they might consider employing. Of course, the usual costs of regulation could easily outweigh its possible benefit. ${ }^{51}$

First, regulators may compel disclosure. For example, regulators could compel printer manufacturers to report the cost of ink of printed page in a prominent place on the product. Indeed, regulators have occasionally adopted such unshrouding policies (e.g., nutritional labeling, energy usage labeling, and financial product labeling). However, disclosure laws for credit cards and mortgages have met with only mixed success [Ausubel 1991; Woodward 2003]. Indeed, in most markets it is difficult to design and enforce a successful disclosure regulation. For example, how would one compel banks to make financial service fees salient? A bank account provides access to thousands of complementary financial services with associated fees (e.g., out-of-network ATM fees, overdraft fees, bounced check fees, etc.). There is no summary statistic like ink cost per page that summarizes bank fees. Regulations will probably not succeed if they simply change the font size of the fine print. Nobody yet knows how to compel transparency. And it remains to be seen whether that is desirable-or possible-in practice.

Second, regulators could simply warn consumers to pay attention to shrouded costs. For example, required "warning labels" could be placed prominently on marketing materials, much like cigarette warning labels. For example, mutual fund marketing materials could be required to contain the following warning label: "Investors are urged to check loads, management fees, and other charges before investing in any mutual fund. If these fees are not reported in marketing materials, do not forget to ask about them." 52

Third, regulators could make add-on markets more competitive. For example, regulators could require that printer manufac-

51. See also Caplin and Leahy [2003] and Jolls and Sunstein [2005] for discussions of policy with biased consumers.

52. The U. K. Treasury is in the midst of a broad expansion of transparency regulation in the banking sector [Cruickshank 2000]. 
turers allow competitive entry in the printer cartridge market. Right now, most printer manufacturers prevent such entry by designing cartridges with integrated patented printer heads (instead of incorporating the printer head into the printer itself). Hall [2003] contains an analysis of this anticompetitive practice. The famous Kodak copier case [Klein 1993] presents another example of an add-on market in which competition was effectively eliminated, resulting in a Supreme Court decision against the aftermarket monopoly. However, we tend to be skeptical of regulations that prevent companies from exerting market power. Such procompetitive regulations may have the unintended negative consequence of discouraging technological innovation.

Finally, regulators may impose markup caps on shrouded attributes. For example, Singapore regulates the markup the hotel charges for the phone. ${ }^{53}$ However, even if good theoretical arguments exist for regulating shrouded fees, such regulations put us on a slippery slope that may produce great unintended harm. Mark-up regulations are often counterproductive.

\section{Conclusion}

Firms often shroud the negative attributes of their products, particularly high prices for complementary add-ons. Following a suggestion by Ellison [2005], we present a model of consumer myopia that explains such shrouding. We identify conditions under which shrouding survives in competitive equilibrium. We show that competition will not induce firms to reveal information that would improve market efficiency. Firms will not educate the public about the add-on market, even when unshrouding is free.

A "curse of debiasing" suppresses unshrouding. Debiasing a consumer improves consumer welfare, but no firm can capture or even partially share these benefits. Firms receive lower profits when they interact with debiased consumers. Debiased consumers know how to avoid high-priced items. Moreover, firms cannot drive away such debiased consumers without losing (profitable) myopic consumers as well. Debiased consumers can pretend to be myopes, enabling the debiased consumers to take advantage of the traps that firms set for myopes.

53. Singapore requires that hotels price their international phone calls at marginal cost, plus a maximum of 30 Singaporean cents (which is about 20 U. S. cents). See Singapore Telecommunications Act [2000]. We thank Ben Olken for this example. 
The economics of shrouding suggest some new research questions. We would like to measure the scope of firms' efforts to shroud information. We would like to measure the degree of consumer myopia. Finally, we would like to know how quickly learning unshrouds information and how quickly the fog returns as firms introduce new products and "better" marketing techniques.

\section{Appendix 1: The Demand Function $D(x)$}

We define $D(x)$ as the demand of a firm that offers an average perceived surplus $x$ units greater than the average perceived surplus provided by its competitors. We develop the microfoundations for $D(x)$ using random utility theory (see Anderson, de Palma, and Thisse [1992] for an excellent review). We assume that good $i$ gives agent $a$ decision utility equal to $U_{a i}=v_{i}-p_{i}+$ $\varepsilon_{a i}$, where $\varepsilon_{a i}$ is i.i.d. across firms $i$ and agents $a$, with cumulative distribution function $F$ and density $f=F^{\prime}$. We interpret $\varepsilon_{a i}$ as a tremble or an idiosyncratic consumer preference [McFadden 1981]. We normalize the mass of consumers to 1 . The demand for firm $i$ is thus $D_{i}=P\left(v_{i}-p_{i}+\varepsilon_{a i} \geq \max _{j \neq i} v_{j}-p_{j}+\varepsilon_{a j}\right)$. We will be looking for symmetric equilibria where a firm posts quality $v$ and prices $p$, while the other firms post the same quality $v^{*}$ and price $p^{*}$, and all firms have the same $\sigma$. In those cases, one can set $S=v-p$ and $S^{*}=v^{*}-p^{*}$, introducing shorthand for the net average surpluses. Then the demand for firm 1 is $D_{1}=D(S-$ $S^{*}$, where we define

$$
D(x) \equiv P\left(x+\varepsilon_{1} \geq \max _{j=2, \ldots, n} \varepsilon_{j}\right)=\int_{-\infty}^{\infty} f(\varepsilon) F^{n-1}(x+\varepsilon) d \varepsilon .
$$

See Perloff and Salop [1985] or Anderson, de Palma, and Thisse [1992]. The demand depends only on the difference $S-S^{*}$ between the surplus $S$ offered by the firms, and the surplus $S^{*}$ offered by its competitors. The following lemma characterizes the symmetric equilibrium.

Lemma 1. Suppose that $\ln f$ is concave, and that firms compete in prices, and have identical costs $c$ and values $v$, so that the profit of a firm charging $p$ is $(p-c) D\left(p^{*}-p\right)$. Then there is a unique symmetric equilibrium with $p-c=\mu:=$ $D(0) / D^{\prime}(0)$. Also, 


$$
\mu D(0)=\max _{x} x D(-x+\mu) .
$$

Proof of Lemma 1. The existence of the symmetric equilibrium is guaranteed by Caplin and Nalebuff [1991, Theorem 2 and Proposition 7]. If marginal costs are $c$ and profits are $(p-$ c) $D\left(p^{*}-p\right)$, the first-order condition is $D\left(p^{*}-p\right)-(p-$ c) $D^{\prime}\left(p^{*}-p\right)=0$. In the symmetric equilibrium, $p=p^{*}$, and so $p-c=\mu$. Finally, equation (17) just reflects that a price $p=$ $p^{*}=\mu$ is an equilibrium if $c=0$.

A few cases have compact closed forms. If the noise is Gumbel distributed, i.e., $F(\varepsilon)=\exp \left(-e^{-\varepsilon}\right)$, the demand is logistic: $D(x)=$ $1 /\left[1+(n-1) e^{-x}\right]$. If the noise is exponentially distributed with density $e^{-\varepsilon} 1_{\varepsilon>0}$, the demand is $D(x)=e^{x}\left[1-1_{x \geq 0}\left(1-e^{-x}\right)^{n}\right] / n$. If the noise is uniformly distributed in $[-1 / 2,1 / 2]$, then $D(x)=0$ for $x<-1, D(x)=(1+x)^{n} / n$ for $x \in[-1,0], D(x)=x+(1-$ $\left.x^{n}\right) / n$ if $x \in[0,1]$, and $D(x)=1$ for $x>1$.

\section{Appendix 2: Longer Deviations}

Proof of Proposition 1. The timeline is detailed in Section II. We specify the sequential equilibrium of the game. We use the terminology from Fudenberg and Tirole [1991, pp. 337-341]. We call $p^{*}$ and $\hat{p}^{*}$ the equilibrium prices at other firms for the base good and the add-on, respectively, and we call $p$ and $\hat{p}$ the prices at firm $i$. We call $\tilde{\hat{p}}$ and $\tilde{\hat{p}}^{*}$ the beliefs of the sophisticated consumers about add-on prices. We need to check sequential rationality and consistency of the beliefs and actions. If a firm unshrouds $\hat{p}$, then the sophisticated consumers know $\hat{p}$, which pins down their belief. If a firm shrouds $\hat{p}$, then sophisticated consumers rationally believe that the firm will charge the monopoly price in period $2: \tilde{\hat{p}}=\bar{p}$, as this is the profitmaximizing price for the firm that shrouds. Given the belief $\tilde{\hat{p}}=\bar{p}$, the sequentially rational action for the sophisticated consumers is to exert the effort $e$. Hence sequential equilibrium very simply characterizes the beliefs of sophisticated consumers and the newly educated myopes, who behave exactly like sophisticated consumers. The beliefs of the myopes do not matter, as they just pick with equal probability a firm among the firms that charge the lowest base good prices.

We now check that firm $i$ does not want to deviate from the announced strategies.

Case 1: $\alpha>\alpha^{\dagger}$ and the Shrouded Prices Equilibrium. 
- Firm $i$ can shroud and pick $p$ and $\hat{p}$. Its profit is equal to

$$
\pi=\left(p+\alpha \hat{p} 1_{\hat{p} \leq \bar{p}}\right) D\left(p^{*}-p\right),
$$

as the beliefs are $\tilde{\hat{p}}=\tilde{\hat{p}}^{*}=\bar{p}$ and the demand for the base good of all the consumers depends only on $p^{*}-p$. This profit is clearly maximized when $\hat{p}=\bar{p}$ so that

$$
\pi=(p+\alpha \bar{p}) D\left(p^{*}-p\right) .
$$

The base-good price $p$ that solves the first-order condition $-(p+\alpha \bar{p}) D^{\prime}\left(p^{*}-p\right)+D\left(p^{*}-p\right)=0$ for $p=p^{*}$ is $p=p^{*}=-\alpha \bar{p}+\mu$.

- Firm $i$ can unshroud and pick $p$ and $\hat{p}$. By unshrouding its add-on price, firm $i$ educates some of the myopes and the fraction of myopes becomes $\alpha^{\prime}=(1-\lambda) \alpha$. The myopes keep ignoring the price of the add-on when deciding to buy the add-on while the sophisticates incorporate it and will buy it if and only if $\hat{p} \leq e$.

- If $\hat{p} \leq e$,

$$
\begin{aligned}
\pi=\left(1-\alpha^{\prime}\right)(p+\hat{p}) D(-p-\hat{p}+ & \left.p^{*}+e\right) \\
& +\alpha^{\prime}(p+\hat{p}) D\left(p^{*}-p\right),
\end{aligned}
$$

which is maximized when $\hat{p}=e$. Otherwise, firm $i$ can increase $\hat{p}$ by a small positive increment, decrease $p$ by the same increment, and not change the demand of sophisticated consumers while increasing strictly the demand of naive consumers. Hence, the profit can be reexpressed as

$$
\pi=(p+e) D\left(p^{*}-p\right) .
$$

As $\alpha>\alpha^{\dagger}$, this profit is smaller than $(p+\alpha \bar{p}) D\left(p^{*}-\right.$ $p$ ), the profit firm $i$ could achieve by choosing to shroud and price at $p$ and $\hat{p}=\bar{p}$.

- If $\hat{p}>e$,

$$
\pi=\left(p+\alpha^{\prime} \hat{p} 1_{\hat{p} \leq \bar{p}}\right) D\left(p^{*}-p\right),
$$

which is strictly smaller than $(p+\alpha \bar{p}) D\left(p^{*}-p\right)$, the profit firm $i$ could achieve by choosing to shroud and price at $p$ and $\hat{p}=\bar{p}$. 
- We conclude that the best response of firm $i$ is to shroud and price at $p=p^{*}=-\alpha \bar{p}+\mu$ and $\hat{p}=\hat{p}^{*}=\bar{p}$.

Case 2: $\alpha<\alpha^{\dagger}$ and the Unshrouded Prices Equilibrium.

- Firm $i$ can unshroud and pick $p$ and $\hat{p}$.

- If $\hat{p} \leq e$,

$$
\begin{aligned}
\pi=\left(1-\alpha^{\prime}\right)(p+\hat{p}) D(-p-\hat{p}+ & \left.p^{*}+e\right) \\
& +\alpha^{\prime}(p+\hat{p}) D\left(p^{*}-p\right),
\end{aligned}
$$

which is maximized when $\hat{p}=e$. Otherwise, firm $i$ can increase $\hat{p}$ by a small positive increment, decrease $p$ by the same increment, and not change the demand of sophisticated consumers while increasing strictly the demand of naive consumers. Hence $\pi=(p+e) D\left(p^{*}-\right.$ $p)$. In equilibrium, the base-good price $p$ solves the first-order condition, $-(p+e) D^{\prime}\left(p^{*}-p\right)+D\left(p^{*}-\right.$ $p)=0$. This implies that $p=p^{*}=-e+\mu$.

- If $\hat{p}>e$, only myopes buy the add-on, and

$$
\pi=\left(p+\alpha^{\prime} \hat{p} 1_{\hat{p} \leq \bar{p}}\right) D\left(p^{*}-p\right) .
$$

This profit is clearly maximized when $\hat{p}=\bar{p}$. The profit is $\pi=\left(p+\alpha^{\prime} \bar{p}\right) D\left(p^{*}-p\right)$, which is strictly smaller than $(p+e) D\left(p^{*}-p\right)$, the profit firm $i$ could achieve by choosing to unshroud and price at $p$ and $\hat{p}=e$.

- Firm $i$ can shroud and pick $p$ and $\hat{p}$ and get a profit equal to

$$
\pi=\left(p+\alpha^{\prime} \hat{p} 1_{\hat{p} \leq \bar{p}}\right) D\left(p^{*}-p\right),
$$

as the beliefs are $\tilde{\hat{p}}=\bar{p}$. One needs $\alpha^{\prime}$ rather than $\alpha$ in the above expression, because the other firms unshroud, so they educate a fraction $\lambda$ of the myopes. This profit is clearly maximized when $\hat{p}=\bar{p}$. The profit is $\pi=(p+$ $\left.\alpha^{\prime} \bar{p}\right) D\left(p^{*}-p\right)$, which is also strictly smaller than the profit firm $i$ could achieve by choosing to unshroud and price at $p$ and $\hat{p}=e$.

- We conclude that the best response of firm $i$ is to unshroud and price at $p=p^{*}=-e+\mu$ and $\hat{p}=\hat{p}^{*}=e$.

Proof of Proposition 3. We follow closely the proof of Proposition 1. The firm's optimal value $\hat{p}$ must still be either $e$ or $\bar{p}$. 
Recall that $\alpha^{\prime}=(1-\lambda) \alpha$ represents the fraction of myopic consumers after unshrouding. If the firm unshrouds, its profit depends on whether $\hat{p}=e$ or $\hat{p}=\bar{p}$ :

$$
\begin{aligned}
& \Pi(\hat{p}=e)=\max _{p}\left(p+\left[\left(1-\alpha^{\prime}\right) T_{S}+\alpha^{\prime}\left(T_{M M}+T_{M S}\right)\right] e\right) D\left(p^{*}-p\right), \\
& \text { (19) } \quad \Pi(\hat{p}=\bar{p})=\max _{p}\left(p+\alpha^{\prime} \bar{p} T_{M M}\right) D\left(p^{*}-p\right) .
\end{aligned}
$$

If it does not unshroud, its profit is

$$
\Pi=\max _{p}\left(p+\alpha T_{M M} \bar{p}\right) D\left(p^{*}-p\right) .
$$

To compare the profits, observe that

$$
\begin{aligned}
{\left[\left(1-\alpha^{\prime}\right) T_{S}+\alpha^{\prime}\left(T_{M M}+T_{M S}\right)\right] e } & \leq \max \left(T_{S}, T_{M M}+T_{M S}\right) e \\
& <\alpha \bar{p} T_{M M}
\end{aligned}
$$

as $\alpha>\alpha^{\dagger \dagger}$. This implies that $\Pi(\hat{p}=e)<\Pi$. Unshrouding and posting a low price $e$ for the add-on is not profitable. Also, $\Pi(\hat{p}=$ $\bar{p})<\Pi$ by equation (19), (20), and $\alpha>\alpha^{\prime}$. Unshrouding and posting a high price $\bar{p}$ for the add-on is also not profitable.

We conclude that whatever price the firm chooses to charge for the add-on, unshrouding is not profitable.

Proof of Proposition 4. We define the average demand in the add-on market as

$$
\hat{\bar{q}}(\hat{p}) \equiv(1-\alpha) \hat{q}^{S}(\hat{p})+\alpha \hat{q}^{M}(\hat{p}) .
$$

In this proof we call $p^{*}$ and $\hat{p}^{*}=\hat{p}^{m}$ the equilibrium prices described in the proposition. We check that the shrouded prices in the proposition constitute an equilibrium.

First, it is clear that if a firm shrouds, the add-on price is the monopoly price $\hat{p}^{m}$. We check that the optimal base-good price is the one announced in equation (10). Without loss of generality, we take $c=0$ to simplify exposition. ${ }^{54}$ The profits are

$$
\Pi=\left(p+\left(\hat{p}^{m}-\hat{c}\right) \hat{\bar{q}}\left(\hat{p}^{m}\right)\right) D\left(-p+p^{*}\right) .
$$

If $p$ is an equilibrium, $\partial \Pi / \partial p=0$ at $p=p^{*}$. This implies that $p+$ $\left(\hat{p}^{m}-\hat{c}\right) \hat{\bar{q}}\left(\hat{p}^{m}\right)=D(0) / D^{\prime}(0)=\mu$, which is equation (10).

54. To go back to the general case, replace $p$ by $p-c$. 
We now calculate the profit of a firm that deviates, unshrouds, and sets new prices $p$ and $\hat{p}$, while the other firms keep shrouding and using the prices $p^{*}$ and $\hat{p}^{*}$ given in equations (10)-(11). A sophisticate facing price $\hat{p}$ in the aftermarket gets the net utility

$$
\hat{v}(\hat{p})=\max _{\hat{q}, \hat{e}} \hat{u}(\hat{e}, \hat{q})-\hat{p} \hat{q} .
$$

Call $\hat{q}(\hat{p})$ (or $\hat{q}^{S}(\hat{p})$ if there is an ambiguity) the associated choice of add-on demand, and $\hat{u}(\hat{p})=\hat{v}(\hat{p})+\hat{p} \hat{q}(\hat{p})$ the gross utility. The utility provided by the other firms is $u^{S^{*}}=-p^{*}+\hat{v}\left(\hat{p}^{*}\right)$.

The firm's profit is

$$
\begin{array}{r}
\Pi=(p+(\hat{p}-\hat{c}) \hat{q}(\hat{p})) D\left(-p+\hat{v}(\hat{p})-u^{S^{*}}\right)=x D(-x+(\hat{p}-\hat{c}) \hat{q}(\hat{p}) \\
\left.+\hat{v}(\hat{p})-u^{S^{*}}\right),
\end{array}
$$

where $x=p+(\hat{p}-\hat{c}) \hat{q}(\hat{p})$ is the total profit per customer. Maximizing $\Pi(x, \hat{p})$ over $\hat{p}$ and noting that (22) and the envelope theorem imply $(\partial / \partial \hat{p}) \hat{v}(\hat{p})=-\hat{q}(\hat{p})$, we get

$$
\begin{aligned}
0=\frac{\partial}{\partial \hat{p}}[(\hat{p}-\hat{c}) \hat{q}(\hat{p})+\hat{v}(\hat{p})]=\hat{q}(\hat{p})-\hat{q}(\hat{p})+ & (\hat{p}-\hat{c}) \hat{q}^{\prime}(\hat{p}) \\
& =(\hat{p}-\hat{c}) \hat{q}^{\prime}(\hat{p}) .
\end{aligned}
$$

This implies that $\hat{p}-\hat{c}=0$. When a firm faces only sophisticated consumers, it prices the add-on efficiently. So the highest profit the firm can get after deviating is

$$
\Pi=\max _{x} x D\left(-x+x^{*}\right),
$$

with $x^{*}=\hat{v}(\hat{c})-u^{S^{*}}$.

As the predeviation profit is $\mu$, the firm does not want to deviate if and only if

$$
\Pi \leq \mu D(0),
$$

as $\mu D(0)$ is the predeviation profit. Given equations (17) and (23), and the fact that $\max _{x} x D(-x+z)$ is nondecreasing in $z$, (24) is equivalent to $x^{*} \leq \mu$. To find the sign of $x^{*}-\mu$, we calculate 


$$
\begin{aligned}
& x^{*}-\mu=\hat{v}(\hat{c})-u^{S^{*}}-\mu=\hat{v}(\hat{c})-\hat{v}\left(\hat{p}^{*}\right)+p^{*}-\mu \\
& =\hat{v}(\hat{c})-\hat{u}^{S}\left(\hat{p}^{*}\right)+\hat{p}^{*} \hat{q}^{S}\left(\hat{p}^{*}\right) \\
& -\left(\hat{p}^{*}-\hat{c}\right) \hat{\bar{q}}\left(\hat{p}^{*}\right) \text { by }(10) \text { and }(22) \\
& =\hat{v}(\hat{c})-\hat{u}^{S}\left(\hat{p}^{*}\right)+\hat{p}^{*} \hat{q}^{S}\left(\hat{p}^{*}\right)-\left(\hat{p}^{*}-\hat{c}\right) \\
& \times\left[(1-\alpha) \hat{q}^{S}\left(\hat{p}^{*}\right)+\alpha \hat{q}^{M}\left(\hat{p}^{*}\right)\right] \text { by }(21) \\
& =\hat{u}(\hat{c})-\hat{c} \hat{q}^{S}(\hat{c})-\hat{u}^{S}\left(\hat{p}^{*}\right)+\hat{c} \hat{q}^{S}\left(\hat{p}^{*}\right)-\alpha\left(\hat{p}^{*}-\hat{c}\right) \\
& \times\left(\hat{q}^{M}\left(\hat{p}^{*}\right)-\hat{q}^{S}\left(\hat{p}^{*}\right)\right) \text { by }(22) \text {. }
\end{aligned}
$$

As the firm does not want to deviate if and only if $x^{*}-\mu \leq 0$, the proposition is proved.

Massachusetts Institute of Technology and National Bureau of Economic RESEARCH

HaRvard University and National BuREau of Economic RESEARCH

\section{REFERENCES}

Agarwal, Sumit, John Driscoll, Xavier Gabaix, and David Laibson, "Fool Me Twice," manuscript, Harvard University, 2005.

Anderson, Simon, André de Palma, and Jacques-Francois Thisse, Discrete Choice Theory of Product Differentiation (Cambridge, MA: MIT Press, 1992).

Ausubel, Lawrence, "The Failure of Competition in the Credit Card Market," American Economic Review, CXXXI (1991), 50-81.

Ayres, Ian, and Barry Nalebuff, "In Praise of Honest Pricing," MIT Sloan Management Review, XLV (2003), 24-28.

Bagwell, Kyle, "The Economic Analysis of Advertising," in M. Armstrong and R. Porter, eds., Handbook of Industrial Organization, Volume III (Amsterdam: North-Holland, 2005).

Barber, Brad M., Terrance Odean, and Lu Zheng, "Out of Sight, out of Mind: The Effects of Expenses on Mutual Fund Flows," Journal of Business, forthcoming.

Becker, Gary, The Economics of Discrimination (Chicago, IL: University of Chicago Press, 1957).

Bertrand, Marianne, Dean Karlan, Sendhil Mullainathan, Eldar Shafir, and Jon Zinman, "What's Psychology Worth? A Field Experiment in the Consumer Credit Market," mimeo, 2005.

Borenstein, Severin, Jeffrey MacKie-Mason, and Janet Netz, "Antitrust Policy in Aftermarkets," Antitrust Law Journal, LXIII (1995), 455-482.

Butters, Gerard R., "Equilibrium Distributions of Sales and Advertising Prices," Review of Economic Studies, XLIV (1977), 465-491.

Campbell, John Y., "Household Finance," Harvard Working Paper, 2006.

Caplin, Andrew, and John Leahy, "Behavioral Policy," in Isabelle Brocas and Juan Carrillo, eds., The Psychology of Economic Decisions: Vol. 1, Rationality and Well-Being (Oxford: Oxford University Press, 2003).

Caplin, Andrew, and Barry Nalebuff, "Aggregation and Imperfect Competition: On the Existence of Equilibrium," Econometrica, LIX (1991), 25-60.

Choi, James, Brigitte Madrian, and David Laibson, "Why Does the Law of One Price Fail? An Experiment on Index Mutual Funds," Harvard mimeo, December 2005.

Cruickshank, Donald, Review of Banking Services in the UK (London: HM Treasury, 2000). 
DellaVigna, Stefano, and Ulrike Malmendier, "Contract Design and Self-Control: Theory and Evidence," Quarterly Journal of Economics, CXIX (2004), 353-402.

DellaVigna, Stefano, and Ulrike Malmendier, "Paying Not To Go To The Gym," American Economic Review, forthcoming.

Diamond, Peter, "A Model of Price Adjustment," Journal of Economic Theory, III (1971), 156-168.

Ellison, Glenn, "A Model of Add-on Pricing," Quarterly Journal of Economics, CXX (2005), 585-638.

— - "Bounded Rationality in Industrial Organization," in Whitney Newey, Torsten Persson, and Richard Blundell eds., Advances in Economics and Econometrics: Theory and Applications, Ninth World Congress (Cambridge, UK: Cambridge University Press, forthcoming).

Ellison, Glenn, and Sara Fisher Ellison, "Search, Obfuscation, and Price Elasticities on the Internet," NBER Working Paper No. 10570, 2004.

Farrell, Joseph, and Paul Klemperer, "Coordination and Lock-In: Competition with Switching Costs and Network Effects," in M. Armstrong and R. Porter, eds., Handbook of Industrial Organization, Volume III (Amsterdam: NorthHolland, 2005).

Fudenberg, Drew, and Jean Tirole, Game Theory (Cambridge, MA: MIT Press, 1991).

Gabaix, Xavier, David Laibson, and Hongyi Li, "Extreme Value Theory, Competition and Consumer Confusion," mimeo, Harvard University and Massachusetts Institute of Technology, 2005.

Gabaix, Xavier, David Laibson, Guillermo Moloche, and Stephen Weinberg, "Costly Information Acquisition: Experimental Analysis of a Boundedly Rational Model," American Economic Review, forthcoming.

Glaeser, Edward, "The Political Economy of Hatred," Quarterly Journal of Economics, CXX (2005), 45-86.

Hall, Robert, "The Inkjet Aftermarket: An Economic Analysis," Working Paper, Stanford University, 2003.

Hausman, Jerry A., "Individual Discount Rates and the Purchase and Utilization of Energy-Using Durables," Bell Journal of Economics, X (1979), 33-54.

Hausman, Jerry A., and Paul L. Joskow, "Evaluating the Costs and Benefits of Appliance Efficiency Standards," American Economic Review, LXXII (1982), $220-225$.

Heidhues, Paul, and Botond Koszegi, "Loss Aversion, Price Stability, and Sales," Working Paper, University of California, Berkeley, 2005.

Hortacsu, Ali, and Chad Syverson, "Product Differentiation, Search Costs, and Competition in the Mutual Fund Industry: A Case Study of S\&P 500 Index Funds," Quarterly Journal of Economics, CXIX (2004), 403-456.

Hossain, Tanjin, and John Morgan, "Shrouded Attributes and Information Suppression: Evidence from Field Experiments," mimeo, University of California, Berkeley, 2005.

Hossain, Tanjim, and John Morgan, “... Plus Shipping and Handling: Revenue (Non)Equivalence in Field Experiments on eBay," Advances in Economic Analysis and Policy, VI (2006).

Jin, Ginger, and Philip Leslie, "The Effect of Information on Product Quality: Evidence from Restaurant Hygiene Grade Cards," Quarterly Journal of Economics, CXVIII (2003), 409-451.

Jolls, Christine, and Cass R. Sunstein, "Debiasing Through Law," NBER Working Paper No. 11738, 2005.

Jovanovic, Boyan, "Truthful Disclosure of Information," Bell Journal of Economics, XIII (1982), 36-44.

Klein, Benjamin, "Market Power in Antitrust: Economic Analysis after Kodak," Supreme Court Economic Review, III (1993), 43-92.

Klemperer, Paul, "Markets with Consumer Switching Costs," Quarterly Journal of Economics, CII (1987), 375-394.

Kószegi, Botond, and Matthew Rabin, "A Model of Reference-Dependent Preferences," Quarterly Journal of Economics, CXXI (2006), forthcoming.

Laibson, David, and Leeat Yariv, "Safety in Markets: An Impossibility Theorem for Dutch Books," mimeo, University of California, Los Angeles, 2005. 
Lal, Rajiv, and Carmen Matutes, "Retail Pricing and Advertising Strategies," Journal of Business, LXVII (1994), 345-370.

Landier, Augustin, and David Thesmar, "Optimistic Beliefs as Private Benefits for Entrepreneurs: Implications for Contracting and Evidence," Working Paper, New York University, 2005.

Lazear, Edward P., "Bait and Switch," Journal of Political Economv, CIII (1995), 813-830.

Malmendier, Ulrike, and Devin Shanthikumar, "Are Small Investors Naive about Incentives?" mimeo, Harvard University and Stanford University, 2005.

McFadden, Daniel, "Econometric Models of Probabilistic Choice," in C. Manski and D. McFadden, eds., Structural Analysis of Discrete Data (Cambridge, MA: MIT Press, 1981).

Miao, Chun-Hui, "Consumer Myopia, Standardization, and Aftermarket Monopolization," mimeo, Princeton University, 2005.

Milgrom, Paul, "Good News and Bad News: Representation Theorems and Applications," Bell Journal of Economics, XII (1981), 380-391.

Morwitz, Vicki, Eric A. Greenleaf, and Eric J. Johnson, "Divide and Prosper: Consumers' Reactions to Partitioned Prices," Journal of Marketing Research, XXXV (1998), 453-463.

Mullainathan, Sendhil, and Andrei Shleifer, "The Market for News," American Economic Review, XCV (2005), 1031-1053.

Office of Fair Trading, "Consumer IT Goods and Services," United Kingdom, 2002.

Oster, Sharon M., and Fiona M. Scott Morton, "Behavioral Biases Meet the Market: The Case of Magazine Subscription Prices," Advances in Economic Analysis and Policy, V (2005).

Perloff, Jeffrey M., and Steven C. Salop, "Equilibrium with Product Differentiation," Review of Economic Studies, LII (1985), 107-120.

Rogers, Kevin, and Joseph F. Sinkey, "An Analysis of Nontraditional Activities at U. S. Commercial Banks," Review of Financial Economics, VIII (1999), 25-39.

Salop, Steven, "Exclusionary Vertical Restraints Law-Has Economics Mattered?" American Economic Review Papers and Proceedings, LXXXIII (1993), $168-172$.

Salop, Steven, and Joseph Stiglitz, "Bargains and Ripoffs: A Model of Monopolistically Competitive Price," Review of Economic Studies, XLIV (1977), 493-510.

Shapiro, Carl, "Aftermarkets and Consumer Welfare: Making Sense of Kodak," Antitrust Law Journal, LXIII (1995), 483-511.

Shui, Haiyan, and Lawrence Ausubel, "Consumer Time Inconsistency: Evidence from an Experiment in the Credit Card Market," mimeo, University of Maryland, 2004.

Simmons, Carolyn J., and John G. Lynch, Jr., "Inference Effects without Inference Making? Effects of Missing Information on Discounting and Use of Presented Information," Journal of Consumer Research, XVII (1991), 477-491.

Singapore Telecommunications Act (Chapter 323, Section 74) Telecommunications (Class Licenses) Regulations, Part IV, Third Schedule (Class License for Resale of Public Switched Telecommunication Services) (April 1, 2000).

Spence, Michael, "Consumer Mispreceptions, Product Failure, and Producer Liability," Review of Economic Studies, XLIV (1977), 561-572.

Spiegler, Rani, "The Market for Quacks," Working Paper, Tel Aviv University, 2004 .

Stahl, Dale, "Oligopolistic Pricing with Sequential Consumer Search," American Economic Review, LXXIX (1989), 700-712.

Stole, Lars, "Price Discrimination and Imperfect Competition," in M. Armstrong and R. Porter, eds., Handbook of Industrial Organization, Volume III (Amsterdam: North-Holland, 2005).

Woodward, Susan, "Consumer Confusion in the Mortgage Market," Sand Hill Econometrics Research Paper, 2003. 